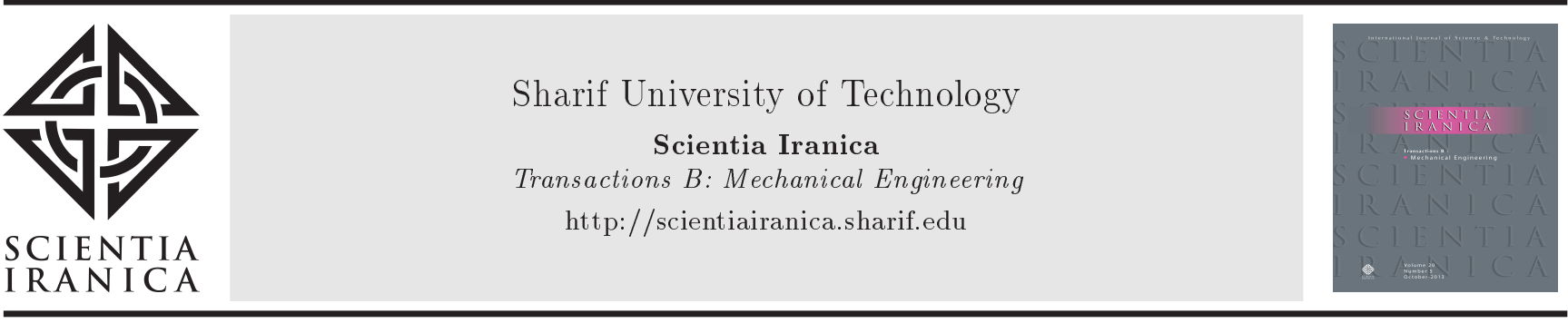

\title{
Electric discharge drilling with gas-assisted multi-hole slotted tool
}

\author{
N.K. Singh ${ }^{\mathrm{a}, 1, *}$, R.K. Upadhyay ${ }^{\mathrm{a}}$, Y. Singh ${ }^{\mathrm{b}}$, and A. Sharma ${ }^{\mathrm{c}}$ \\ a. Department of Mechanical Engineering, Hindustan College of Science and Technology, Mathura, India. \\ b. Department of Mechanical Engineering, Graphic Era Deemed to be University, Dehradun, Uttarakhand, India. \\ c. Department of Mechanical Engineering, GL Bajaj Institute of Technology and Management, Gr. Noida, India. \\ Received 22 January 2020; received in revised form 30 March 2020; accepted 15 June 2020
}

\section{KEYWORDS}

Novel;

Electrode;

Gas;

Rotation;

AAEDD;

Flushing.

\begin{abstract}
This paper proposes the use of a novel electrode containing a modified design intended to promote gas-assisted tool rotation-induced debris removal. The proposed tool was observed to be efficient in dispensing the accumulation of eroded materials from the discharge gaps. In this, study the influence of process parameters like discharge current, tool speed, gas pressure, pulse duration, and duty cycle on output responses is investigated. This outputs responses include: Material Removal Rate (MRR), Electrode Wear Ratio (EWR), and Surface Roughness (SR). A comparative study of the output responses was made with a solid rotary tool and the gas-aided multi-hole slotted tool. The outcome revealed that the application of the multi-hole slotted tool increased the MRR in Air-Aided Electric Discharge Drilling (AAEDD) by 40-80\%. Besides this, the EWR decreased in AAEDD by $17-25 \%$ compared to rotary electric discharge Drilling (REDD). Moreover, the SR of the AAEDD process was comparatively higher (9-15\%) than that of the REDD process. The findings showed less surface crack, micropores and recast layers on specimens machined by the AAEDD process in comparison to the REDD process. This study proposes a novel method for improving the machining performance by improving the flushing efficiency of the machining gap to improve the material removal mechanism.
\end{abstract}

(C) 2021 Sharif University of Technology. All rights reserved.

\section{Introduction}

Electrical Discharge Machining (EDM) is perhaps the most widely used novel method of machining. It is mainly used in the manufacture of molds, dies, and complicated shape profiles [1]. Flushing of debris from the electrode gap is one of the main problems faced in EDM machining. The arcing and short-circuit occurs when the eroded material collected in the inter-

1. Present address: Department of Mechanical Engineering, Sir Padampat Singhania University, Udaipur, India.

*. Corresponding author.

E-mail address: nishant.singh78@gmail.com (N.K. Singh)

doi: $10.24200 /$ sci. 2020.55017 .4030 electrode gap leads to decreased Material Removal Rate (MRR) and poorer surface integrity [2]. In the Electrical Discharge Drilling (EDD) process as the tool progresses further into the specimen, the impact of flushing continues to reduce. During deep drilling, the flushing is inadequate and the eroded materials are difficult to be removed from the inter-electrode gap. The collection of debris in the electrodes gap brings about continuous short-circuiting and results in excess electrode wear and inferior machining [3].

Various researchers have addressed the issue of debris removal from a different perspective. To rectify these issues, various methodologies have been developed by the researchers. One of the remedies of such problems is the application of the rotary tool in 
conventional EDM. Experimental exploration confirms that the rotary electrode significantly improves the EDM performance [4-8]. Wang and Yan [4] studied the influence of the rotary ball burnishing electrode during EDM of $\mathrm{Al}_{2} \mathrm{O}_{3} / 6064 \mathrm{Al}$ composite. The result revealed that the rotary ball burnishing electrode produced a better surface finish with improved machining performance. The application of the proposed tool resulted in a decrease in Surface Roughness (SR) from 55 to $92 \%$ under different processing conditions. Singh et al. [5] explored the impact of electrode geometry on MRR during rotary EDM. They proposed that the use of a tapered-shaped tool would lead to a better material removal when contrasted with the use of conventional or chamfer-shaped electrodes. Aliakbari and Baseri [6] have studied the impact of multi-hole rotary tools on significant EDM process output such as MRR, SR and, Electrode Wear Ratio (EWR). Their results indicated that the multi-hole tool had a significant impact on the performance of the EDM process. To improve the performance of the EDM process, researchers investigated various approaches to the use of the rotary-tool magnetic field during EDM machining $[7,8]$. Their findings suggested that the combined action of the rotating magnetic field, as well as the rotation of the electrode could improve the machining efficiency. These findings showed that the improved machining performance was due to the better flushing efficiency of the discharge gap.

Several studies [9-11] investigated the ability of liquid dielectric supply through the electrode to improve EDM performance. Gu and Zhao [9] carried out EDM machining using a bundled electrode. Results have shown that the eroded materials are effectively removed from the spark gap with the help of the inward flushing of the bundled electrode resulting in improved material removal. Zhao et al. [10] used an innovative flushing technique by using a bunched electrode for bulk material removal in the EDM. They explored the impact of flushing on EDM responses with the help of experiments and simulations. The authors found that the bunched electrode provided efficacious flushing that caused larger MRR and higher EWR. The reason for improvement in flushing may be due to the proposed tool geometry, which increases the rate of removal of debris from the electrode gap. Xu et al. [11] analyzed the impact of flushing through a multi-hole electrode during EDM operation. Their experimental and simulation results indicated that the machining performance was significantly influenced by flushing velocity.

Different studies [12-17] suggested that the supply of compressed gas in the discharge gap causes the effective removal of eroded materials from the machining region resulting in improved EDM performance. Singh and Pandey [12] investigated the impact of the air-assisted multi-hole rotating tool during EDM of high carbon chromium steel. They perceived that the application of the proposed airassisted tool results in a better MRR and a lower EWR compared to a solid rotary tool for the same parametric combinations. During the EDM process, Kuineda and Furuoya [13] provided air and oxygen gas via a tubular tool. Exothermic reactions were noted when oxygen and air were utilized in machining. The additional heat generated by the exothermic reaction attributable to oxygen and air allowed the workpiece materials to melt and evaporate further, resulting in better MRR. Beravala and Pandey [14] noted that the supply of air/argon gas through a multi-hole tool reduced the deposition of eroded materials on the machine surface and enhanced the MRR. Some studies have also suggested that the use of liquid-gas dielectrics may help to improve significant EDM responses. Wang and Shen [15] used different combinations of liquid-gas dielectrics for high-speed EDM milling with a hollow electrode. Experimental findings indicated that the supply of compressed gas-liquid results in a better MRR compared to the supply of dielectric gas. A groundbreaking approach to the study of the effects of gas-liquid mixing using tomography with electrical resistance is also explored [16]. Li and Wataru [17] conducted micro-EDM drilling with mist deionized water jets. Their finding revealed that the employment of a mist deionized water jet improves the rate of removal of eroded materials from the discharge gap during the deep micro-hole drilling process.

The geometry of the electrodes has been reported to be effective in reducing the collection of spark eroded materials in the gap between the electrodes, leading to the improved efficiency of EDM. Nastasi and Koshy [18] used different tools with distinct geometrical features to know their effect on debris removal. Their finding revealed that the slotted tool out-performs the conventional solid tool in terms of MRR. Yan et al. [19] used a notched tool in their exploratory investigation and assumed that a notch tool could effectively improve the removal of debris. Kumar and Singh [20] proposed a tool with an inclined hole during an EDD operation. Their findings showed that the proposed tool has self-flushing characteristics and is more potent in the evacuation of eroded materials from the machining zone than the conventional solid tool. Kumar and Dhanbalan [21] investigated the machinability and tolerances of inconel-718 employing a multi-hole electrode with an engraved hole resulting in increased MRR and a lower tolerance discrepancy. The researchers have also explored the use of different novel reference electrodes in various processes [22-23]. Their finding indicated that novel electrodes have a positive impact on the performance of the process.

As the above-mentioned literature review re- 
vealed, the geometry of the tool is very effective in preventing the accumulation of eroded particles in the machining region. Besides, the supply of gaseous dielectrics through multi-hole rotary electrodes reduces the possibility of arcing and short-circuiting and results in improved EDM performance. Moreover, small clearance of gas flow results in incomplete removal of eroded materials from the electrodes gap. This shortcoming can be eliminated by manufacturing a multihole slotted electrode that can provide a mechanism for easy removal of debris from the inter-electrode gap and can reduce arcing and short-circuiting resulting in a better flushing action. From the literature review, it is apparent that no attempt has been made to incorporate multi-hole slotted rotary electrode and to supply compressed air in the EDD operation. In this research work, compressed air through a multi-hole slotted rotary electrode is provided in the discharge gap to study the influence of airflow on EDD functioning. Some studies have been performed to compare the MRR, EWR, and SR of Air-Assisted Electric Discharge Drilling (AAEDD) and Rotary Electric Discharge Drilling (REDD) processes. The present study aims to create statistical-based models for MRR, EWR, and SR by employing flow air through the multi-hole slotted electrode in EDD operation.

This study was conducted in two phases. The first phase emphasized the establishment of statisticalbased MRR, EWR, and SR models during the AAEDD process. The main effect and interaction effects of different process parameters on process responses, such as MRR, EWR, and SR were analyzed in order to determine the impact of compressed air supply through the multi-hole rotary electrode in the conventional EDD process. The second phase is a comparison between REDD and AAEDD processes relating to MRR, EWR, and SR.

\section{Experimental work}

\subsection{Details of workpiece and electrode material}

The experiment was executed on D3 die steel as a workpiece using copper as the tool material. The specimen had a rectangular shape $(20 \times 15 \times 15 \mathrm{~mm})$. A multi-hole slotted tube was used as a tool to supply high-velocity air through the electrode. As depicted in Table 1, the specimen chemical composition was selected. The hardness of the material has been kept constant (51HRC). Due to the good thermal and electrical conductivity of copper material, a rotary
Table 2. Specific properties of the copper electrode.

\begin{tabular}{cc}
\hline Specifications & Value \\
\hline Purity & $99.9 \%$ \\
Average particle size & $<5 \mu$ \\
Density & $2.99 \mathrm{~g} / \mathrm{cm}^{3}$ \\
Electrical resistance & $120 \Omega$ \\
\hline
\end{tabular}

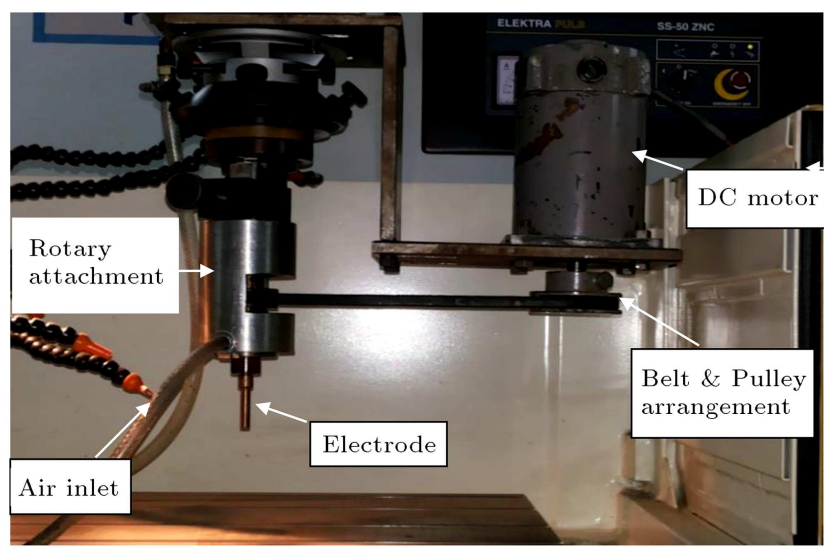

Figure 1. Experimental setup of air-aided Electrical Discharge Machining (EDM).

electrode and a multi-hole slotted electrode of copper were fabricated. A copper attachment was used for maintaining the conductivity of the electrode. The specific property of the copper electrode is shown in Table 2. Figure 1 demonstrates the setup used in the experiments of the present work.

\subsection{Tool design}

To ensure smooth compressed air flow, the appropriate tool geometry was selected. Appropriate tool dimensions were selected to remove maximum heat from the tooltip. The REDD process experiments were conducted with a conventional solid tool with a diameter of $8.35 \mathrm{~mm}$ and a length of $70 \mathrm{~mm}$. The outer diameter and length of the tools used in REDD and AAEDD processes remained the same. The effect of the different numbers of $1 \mathrm{~mm}$ dia. and $1.5 \mathrm{~mm}$ dia. holes $(1,3,5$ holes) were studied in the preliminary experimentation. It was found that the electrode with 3 holes gave higher MRR and lower tool wear rate relatively. The $1.5 \mathrm{~mm}$ diameter holes were penetrated the tool surface at $4 \mathrm{~mm}, 5 \mathrm{~mm}$, and $6 \mathrm{~mm}$ pitch circle diameter. Notwithstanding the way that the machining was upgraded with this design, recurring arcing and short-circuiting happened because of the ineffective expulsion of the eroded debris from electrode

Table 1. Chemical composition of the workpiece.

\begin{tabular}{cccccccc}
\hline Element & C & Si & Cr & Mn & P & S & Fe \\
\hline Wt. (\%) & 2.30 & 0.40 & 10.05 & 0.30 & 0.05 & 0.03 & Rest \\
\hline
\end{tabular}




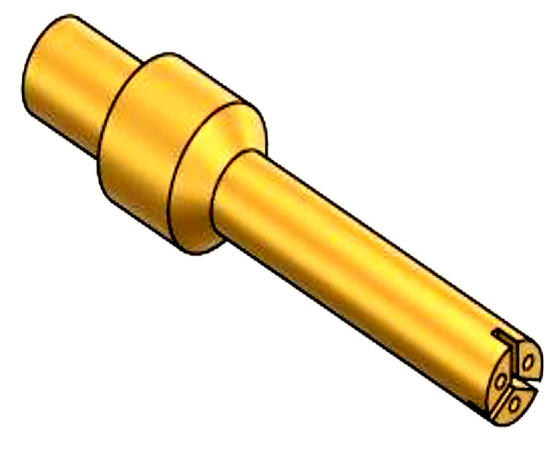

(a)

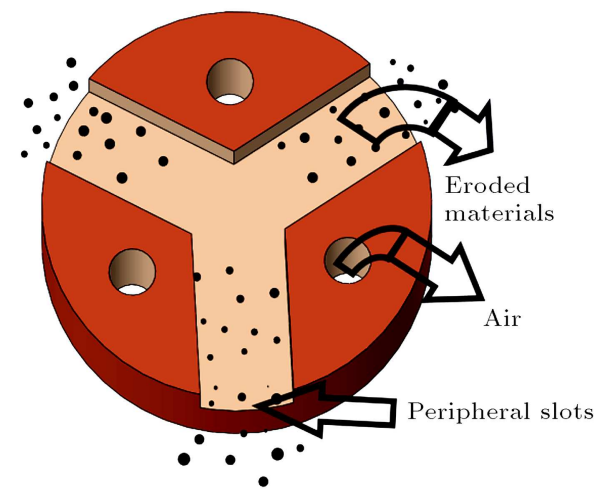

(b)

Figure 2. (a) Schematic of multi-hole slotted tool electrode. (b) Influence of peripheral slots provided on the tool on the flow of spark eroded materials.

gaps. Thus, to rectify such types of problems three slots of size $2 \mathrm{~mm} \times 2 \mathrm{~mm}$ at $120^{\circ}$ apart were provided along the outline of the tool. The use of a multi-hole slotted tool ensured the flow of compressed air through the opening of the arc. The multi-hole slotted tool is shown in Figure 2(a). The chip removal mechanism of slotted electrodes is shown in Figure 2(b). Literature [14] shows that the multi-hole rotating electrode improves the MRR and reduces the electrode wear rate compared to the solid electrode in the airaided EDM process. The gaseous dielectric flowing out of the electrode takes a substantial part of eroded matters and takes away them from the gap between the electrodes. Small passage for this flow however leads to inadequate removal of eroded matter. The debris removal is even very crucial in the EDD process. Hence, to improve the flushing efficiency, the slotted electrode was designed in this study. The slots manufactured into a cylindrical form having multi-holes which provided the shortest path for removal of the debris from the narrow inter-electrode gap. It resulted in an increase in flushing efficiency and reduced the arcing and shortcircuiting events during the EDD process.

\subsection{Experimental procedure}

The AAEDD with the multi-hole slotted tool has been carry-out on an EDM machine. For each experiment, the machining time was suitably chosen which was considered as 25 minutes. It is important to select a rational set of factors to be varied in the experiment. The EDM efficiency is governed by electrical parameters as well as non-electrical parameters. The literature review suggested that among the machining factors the following have a notable impact on EDM performance: the electrical parameters such as discharge current, pulse duration, and duty cycle, and the non-electrical parameters including tool speed, discharge gas pressure. Based on the above observation, five process parameters, i.e., pulse on time, discharge current, duty cycle, electrode speed, and discharge air pressure were chosen. Initially, four parameters were utilized during the REDD and five parameters were considered for the AAEDD process. The main objective of this research was to analyze the effect of the air stream on the EDD performance, and therefore five parameters (the fifth parameter was air pressure) were used in the AAEDD process for the design of the experiments. Table 3 shows the machining factors considered with their levels used during experimentation. EDM oil was used as a liquid dielectric in REDD, while liquid-air mixed dielectric oil was used in the AAEDD process. During the machining process, the electrode was immersed in the liquid dielectric. Moreover, during the AAEDD process, the air was supplied directly into the gap

Table 3. Parameters in the process with their levels.

\begin{tabular}{lccccc}
\hline \multirow{2}{*}{ Factors } & \multicolumn{5}{c}{ Levels } \\
\cline { 2 - 6 } & $\mathbf{- 2}$ & $\mathbf{- 1}$ & $\mathbf{0}$ & $\mathbf{1}$ & $\mathbf{2}$ \\
\hline Discharge current $\left(I_{p}\right)(\mathrm{A})$ & 3 & 4 & 5 & 6 & 7 \\
Pulse on time $\left(T_{o n}\right)(\mu \mathrm{s})$ & 100 & 200 & 300 & 400 & 500 \\
Duty cycle $(\mathrm{DC})$ & 0.52 & 0.58 & 0.64 & 0.70 & 0.76 \\
Tool speed $(\mathrm{rpm})$ & 100 & 300 & 500 & 700 & 900 \\
Discharge air pressure $(\mathrm{AP})(\mathrm{mm} \mathrm{Hg})$ & 3 & 6 & 9 & 12 & 15 \\
\hline
\end{tabular}


through the multi-hole slotted electrode. An opencircuit voltage of $60 \mathrm{~V}$ was maintained constant for all the experiments.

The EWR was calculated as the ratio of the electrode wear to the workpiece erosion [24] and is expressed in percentage.

$$
\operatorname{EWR}(\%)=\frac{\text { Eroded tool weight }}{\text { Eroded workpiece weight }} \times 100 \text {. }
$$

MRR is demonstrated as the ratio of the workpiece erosion weight to the machining time as follows [25]:

$$
\operatorname{MRR}(\mathrm{mg} / \mathrm{min})=\frac{\text { Weight of eroded specimen }}{\text { Machining time }}
$$

All specimen considered for the experimental analysis was cleaned with acetone. To get an exact machining time, the electronic clock having the least count of 0.1 seconds was utilized. A portable SR tester (surf-testSJ-210) having cut-off length of $0.8 \mathrm{~mm}$ and tracing speed of $1.00 \mathrm{~mm} / \mathrm{sec}$ was utilized to measure the Ra value of the machined specimens.

\section{Analysis of experimental outcome}

In the present investigation, the Central Composite Rotatable Design (CCRD) was used to design the experimental plan since it is suitable anticipating quadratic and interaction effects of different process parameters on the process response. The correlation of the deliberate estimations of each trial concerning notable EDD responses for AAEDD and REDD is presented in Figure 3. According to the experimental plan, thirty-two experiments were conducted for AAEDD and thirty-one experiments were performed for REDD. In REDD, four procedure parameters at five levels have been utilized, while, in the AAEDD five parameters with five levels were used for the design of experiments.

Regression analysis of the experimental outcome was carried out to investigate the models, which established the correlation between input parameters (discharge current, tool speed, gas pressure, pulse duration, and duty cycle) and output factors (MRR, EWR, and SR). After eliminating all the insignificant terms, requisite regression models based on the experimental outcomes of the AAEDD process are represented by the following equations.

$$
\begin{aligned}
& M R R=-45.9+\left(0.989 \times I_{p}\right)-\left(0.0243 \times T_{\text {on }}\right) \\
& +(70.1 \times D C)+(0.0223 \times r p m) \\
& +(4.01 \times A P)-\left(0.000023 \times r p m^{2}\right) \\
& -\left(0.0998 \times A P^{2}\right)+\left(0.299 \times I_{p} \times A P\right) \\
& -(5.33 \times D C \times A P), \\
& E W R=-1.29+\left(0.419 \times I_{p}\right)+\left(0.00404 \times T_{\text {on }}\right) \\
& +(1.24 \times D C)+(0.000816 \times r p m) \\
& +(0.018 \times A P)-\left(0.000894 \times I_{p} \times T_{\text {on }}\right) \\
& -(0.000064 \times r p m \times A P), \\
& S R=-15+\left(0.428 \times I_{p}\right)+\left(0.0287 \times T_{\text {on }}\right) \\
& +(24.1 \times D C)+(0.011 \times r p m) \\
& +(0.424 \times A P)-\left(0.015 \times A P^{2}\right) \\
& -\left(0.0404 \times T_{\text {on }} \times D C\right) \\
& -\left(0.000713 \times T_{\text {on }} \times A P\right) \\
& -(0.0203 \times D C \times r p m) \\
& +(0.00034 \times r p m \times A P) .
\end{aligned}
$$

Analysis of variance (ANOVA) was applied to explore the competency of the established model. For a specific Confidence Interval (CI), the F-ratio of the model

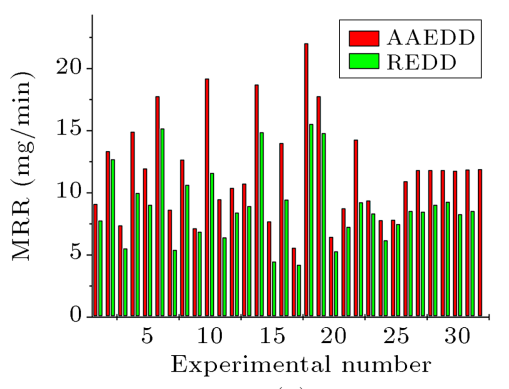

(a)

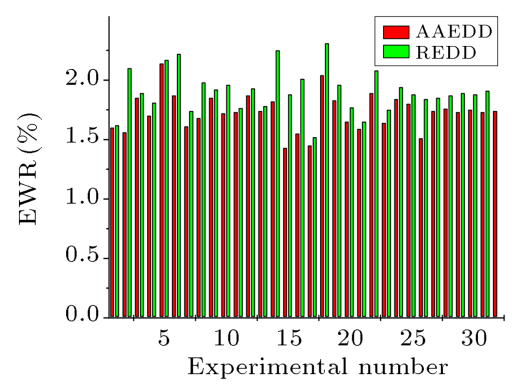

(b)

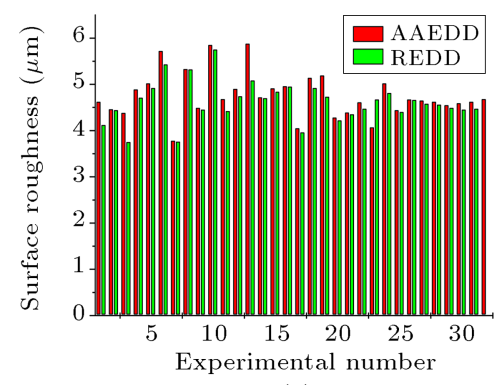

(c)

Figure 3. Comparative study of (a) Material Removal Rate (MRR), (b) Electrode Wear Ratio (EWR), and (c) Surface Roughness (SR) for Air Aided Electric Discharge Drilling (AAEDD), and Rotary Electric Discharge Drilling (REDD) processes. 
Table 4. ANOVA for Material Removal Rate (MRR) in Air Aided Electric Discharge Drilling (AAEDD).

\begin{tabular}{|c|c|c|c|c|c|c|c|}
\hline Source & DF & Seq. SS & MS & $\mathbf{F}$ & $\mathbf{P}$ & $R^{2}$ & \\
\hline Regression & 9 & 603.654 & 67.073 & 49.34 & 0 & 0.952 & $F_{(0.05,9,22)}^{\text {standard }}=2.90$ \\
\hline Linear & 5 & 528.990 & & & & & $F^{\text {regression }}>F_{(0.05,9,22)}^{\text {standard }}$ \\
\hline Square & 1 & 47.101 & & & & & $F_{(0.05,9,22)}^{\text {standard }}=2.90$ \\
\hline Interaction & 3 & 27.563 & & & & & $F^{\text {lack-of-fit }}<F_{(0.05,17,22)}^{\text {standard }}$ \\
\hline Residual error & 22 & 29.908 & 1.359 & & & & $\begin{array}{c}\text { Model is adequate. } \\
\text { There is insignificant } \\
\text { lack of fit. }\end{array}$ \\
\hline Lack-of-fit & 17 & 27.978 & & 2.38 & 0.058 & & \\
\hline Pure error & 5 & 1.929 & & & & & \\
\hline Total & 31 & 633.561 & & & & & \\
\hline
\end{tabular}

Table 5. ANOVA for Electrode Wear Ratio (EWR) in Air Aided Electric Discharge Drilling (AAEDD).

\begin{tabular}{|c|c|c|c|c|c|c|c|}
\hline Source & DF & Seq. SS & MS & $\mathbf{F}$ & $\mathbf{P}$ & $R^{2}$ & \\
\hline Regression & 9 & 4.22621 & 0.46958 & 20.01 & 0 & 0.891 & $F_{(0.05,9,22) ;}^{\text {standard }}=2.762$ \\
\hline Linear & 5 & 2.65045 & & & & & $F^{\text {regression }}>F_{(0.05,9,22)}^{\text {standard }}$ \\
\hline Square & 1 & 0.17519 & & & & & $F_{(0.05,9,22)}^{\text {standard }}=2.762$ \\
\hline Interaction & 3 & 1.40057 & & & & & $F^{l a c k-o f-f i t}<F_{(0.05,17,22)}^{\text {standard }}$ \\
\hline Residual error & 22 & 0.44126 & 0.023 & & & & $\begin{array}{c}\text { Model is adequate. } \\
\text { There is insignificant } \\
\text { lack of fit. }\end{array}$ \\
\hline Lack-of-fit & 17 & 0.47093 & & 1.28 & 0.110 & & \\
\hline Pure error & 5 & 0.04533 & & & & & \\
\hline Total & 31 & 4.74247 & & & & & \\
\hline
\end{tabular}

was estimated and contrasted with the tabulated Fvalue. In the ANOVA of the design of experiments, the measured value of the F-ratio tended to be less than one, and the estimated F-value is less than the $5 \%$ significance level of the tabulated F-value; it is assumed that the impact of the factor under investigation is insignificant. The ANOVA of the second-order model of the AAEDD process is represented in Tables 4, 5, and 6. Eqs. (3), (4), and (5) represent the statistical model of MRR, EWR, and SR. For the developed models, the estimation of "Prob $>F$ " was under 0.05 and considered with a $95 \%$ confidence level. Henceforth, it was revealed that the process factors (discharge current, tool speed, gas pressure, pulse duration, and duty cycle) used in the model had a noteworthy impact on the considered responses.

\subsection{Interaction effect in $A A E D D$}

Figures 4-6 show the effects of the interaction between significant process parameters on MRR, EWR, and SR in the AAEDD process.

\subsubsection{Response surface of $M R R$}

The response surface of MRR for the current and discharge air pressure is illustrated in Figure 4(a). A high MRR was caused by an increase in discharge current. This is due to the increase in discharge energy in the machining region, which has increased the evaporation and melting of the working material [22]. Figure 4(a) shows that the MRR improved with an increase in the air pressure discharge reaching its highest value and then began to decrease with a low discharge current. This can be explained by the fact that the flushing effects of the process improved with a rise in air pressure, which led to a higher MRR [10]. Moreover, plasma channel expansion occurred at higher discharge air pressure and discharge energy was reduced as a result of this, resulting in lower MRR after a certain discharge air pressure value [13]. Figure 4(b) presents the response surface of MRR for air pressure and duty cycle. From the figure, it can be observed that the decrease in the discharge air pressure and duty cycle caused increase in MRR. This could, most likely, 
Table 6. ANOVA for Surface Roughness (SR) in Air Aided Electric Discharge Drilling (AAEDD).

\begin{tabular}{|c|c|c|c|c|c|c|c|}
\hline Source & DF & Seq. SS & MS & $\mathbf{F}$ & $\mathbf{P}$ & $R^{2}$ & \\
\hline Regression & 10 & 15.4711 & 1.54711 & 28.27 & 0 & 0.930 & $F_{(0.05,10,21)}^{\text {standard }}=2.73$ \\
\hline Linear & 5 & 11.5717 & & & & & $F^{\text {regression }}>F_{(0.05,10,21)}^{\text {standard }}$ \\
\hline Square & 1 & 0.5793 & & & & & $F_{(0.0510 .21)}^{\text {standard }}=2.73$ \\
\hline Interaction & 4 & 3.3201 & & & & & $F^{\text {lack-of-fit }}<F_{(0.05,16,21)}^{\text {standard }}$ \\
\hline Residual error & 21 & 1.1494 & 0.054 & & & & $\begin{array}{c}\text { Model is adequate. } \\
\text { There is insignificant } \\
\text { lack of fit. }\end{array}$ \\
\hline Lack-of-fit & 16 & 1.0722 & & 2.23 & 0.056 & & \\
\hline Pure error & 5 & 0.0771 & & & & & \\
\hline Total & 31 & 16.6205 & & & & & \\
\hline
\end{tabular}

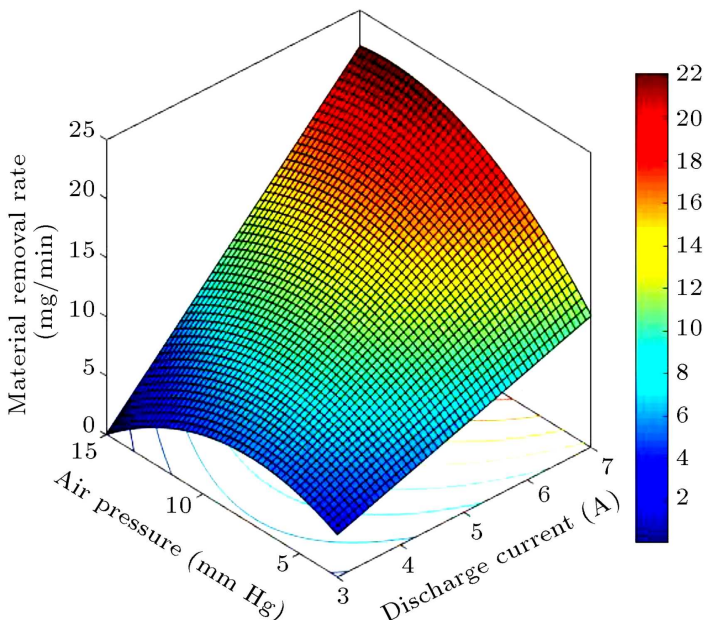

(a)

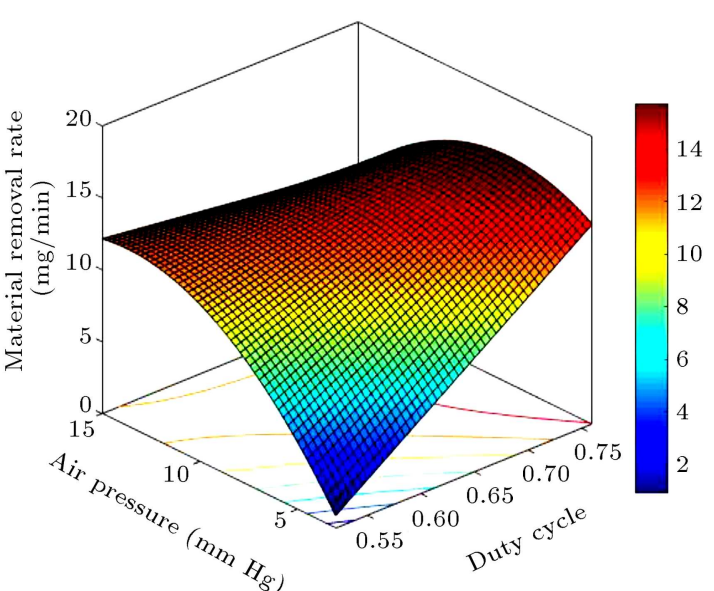

(b)

Figure 4. Response surfaces plot of Material Removal Rate (MRR): (a) Air pressure versus discharge current and (b) air pressure versus duty cycle.

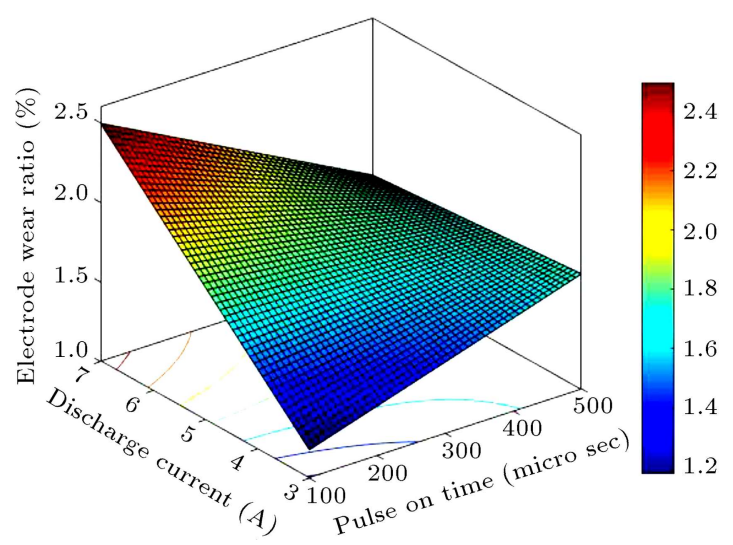

(a)

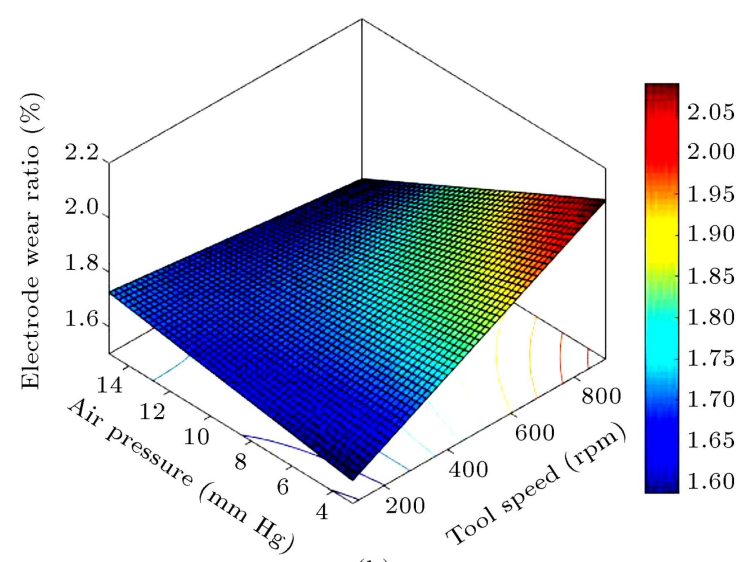

(b)

Figure 5. Response surfaces plots of Electrode Wear Ratio (EWR): (a) Pulse on time versus discharge current and (b) tool speed versus air pressure.

be attributed to the fact the larger value of the duty cycle promoted large spark energy, so it increased the melting and removal of the workpiece material [26]. The increase in air pressure from $3 \mathrm{mmHg}$ to $9 \mathrm{mmHg}$ prompted to improve the flushing of eroded materials from the discharge gap, which resulted in higher MRR [12]. When compressed air was delivered through a multi-hole slotted tool, more turbulence and cavitation were produced, leading to the increased ejection of the molten material. This improved the removal rate and 


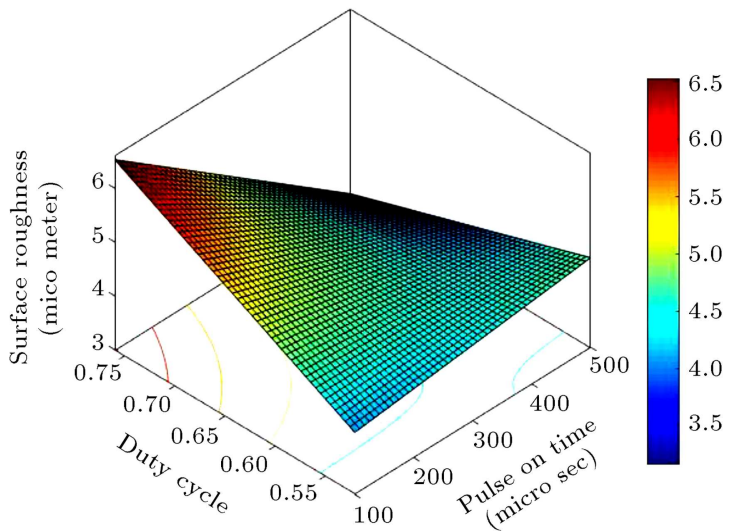

(a)

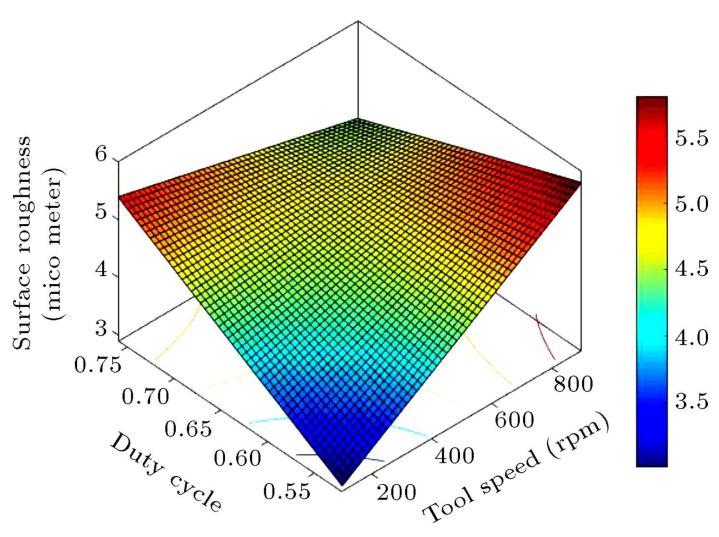

(c)

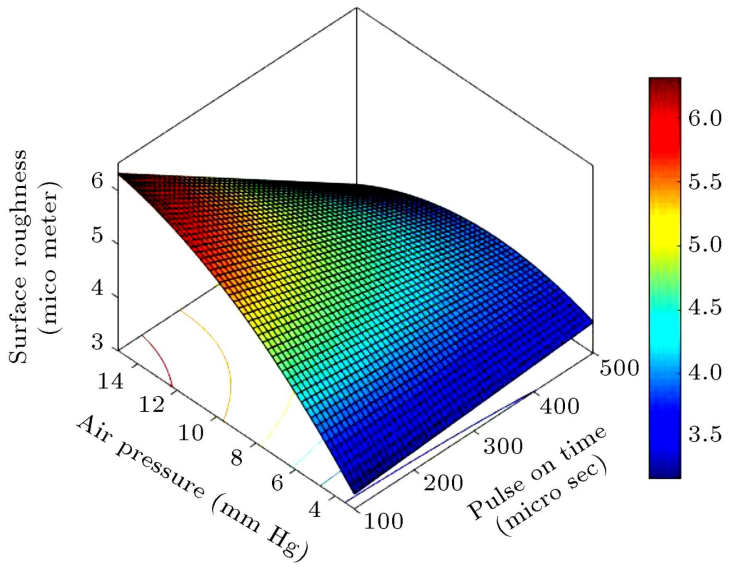

(b)

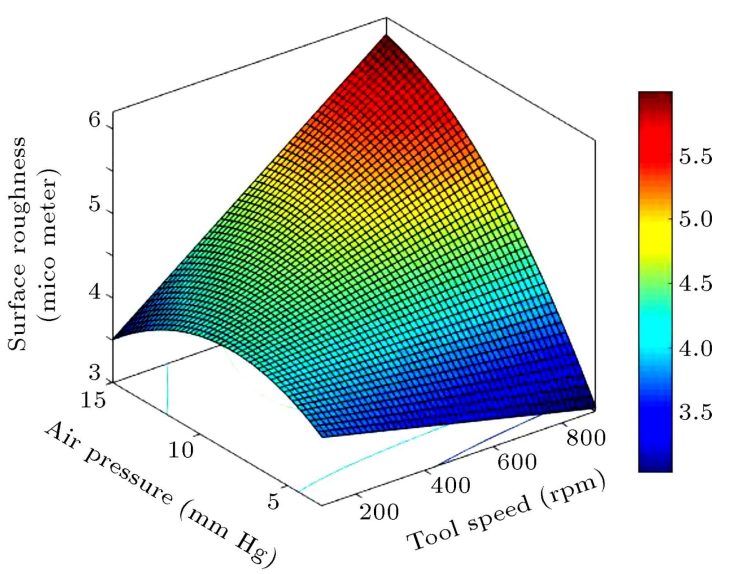

(d)

Figure 6. Response surfaces plots of Surface Roughness (SR): (a) Pulse on time versus duty cycle, (b) pulse on time versus air pressure, (c) tool speed versus duty cycle, and (d) tool speed versus air pressure.

also reduced the amount of liquid material re-deposited to the surface. Shara et al. [23] and Singh et al. [27] have also reported similar findings.

\subsubsection{Response surface of $E W R$}

The response surface of EWR for pulse duration and discharge current is illustrated in Figure 5(a). It is evident from the graph that the effect of high current and low pulse- on-time resulted in higher EWR. The high current has resulted in an increase in discharge energy thus a high temperature was produced. Owing to this extreme heat, the rotating electrode became overheated and the electrode wear increased along with the MRR, thus increasing the EWR [6]. The black carbon was released due to the cracking of hydrocarbon oil sticks in the form of a layer on the surface of the electrode for a longer pulse duration. As a result of the formation of this layer, the resistance against the wear of electrode was created [4]. Figure 5(b) depicts the surface plots of EWR for tool rotation and air pressure. It was observed that EWR increased with an increase in tool speed. As the rotational speed of the tool increased, the extent of the centrifugal force increased. Black carbon particles are expelled from the tool surface due to increased centrifugal force resulting in increased EWR. Patel et al. [24] and Teimouri and Baseri [28] have found similar findings. From Figure 5(b), it was also inferred that the EWR decreased with increment in air pressure. With a rise in discharge air pressure, the flushing action of debris improved, because the MRR of the process improved. However, compressed air flowing through multi-hole slotted tool reduced the tool tip temperature radically and reduced the output size of the tool crater resulting in low tool wear and thus reduced EWR [3].

\subsubsection{Response surface of $S R$}

The response surface of SR for duty cycle and pulseon time is presented in Figure 6(a). From this figure, it can be inferred that the high SR was generated by the combination of high duty cycle and low pulse duration. At high duty cycle, large discharge energy and impetuous force were produced which resulted in larger sized carters on the workpiece, consequently, 
the surface finish decreased with a rise in duty cycle $[21,29]$. At the same time, for high pulse duration, the enlargement of the plasma channel took place in the gap of electrodes, because of which the peak current and magnitude of impulsive force decreased [22]. Thus a shallower carter formed at the surface of the workpiece, which reduced the SR. The response surface of SR for the pulse on time and discharge air pressure is illustrated in Figure 6(b). As it is evident from the illustrated plot a combined set of higher pulse on time with higher discharge air pressure leads to an improvement in surface finish. The higher discharge air pressure facilitated the effective flushing of the eroded particles at lower pulse off-time [3]. The response surface of SR for tool speed and duty cycle is presented in Figure 6(c). From this figure it can be inferred that high SR was generated with an increase in the tool speed and duty cycle. At the high duty cycle, the large discharge energy resulted in larger sized carters on the workpiece $[20,24]$. When the tool speed enhanced the flushing efficiency improved and resulted in less recast layer deposition [30]. The carbon deposition which resulted in bigger size craters and subsequently, high SR is acquired [26]. Figure 6(d) depicts the surface plots of SR for tool rotation and air pressure. The interaction plot revealed that an increase in tool speed and discharge air pressure caused the SR to be increased. Because of an increase in tool rpm and air

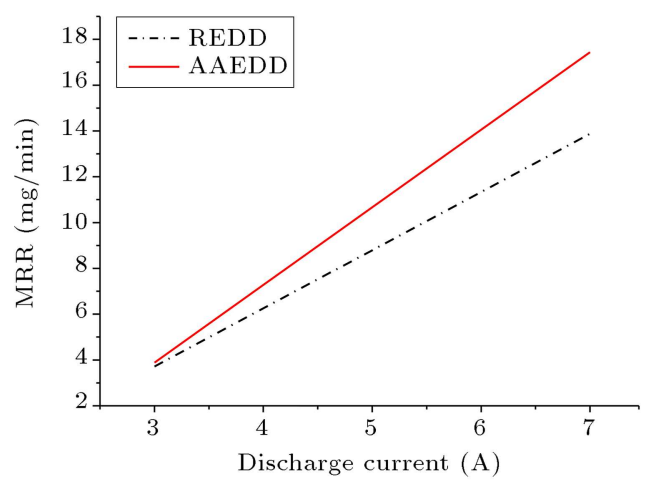

(a)

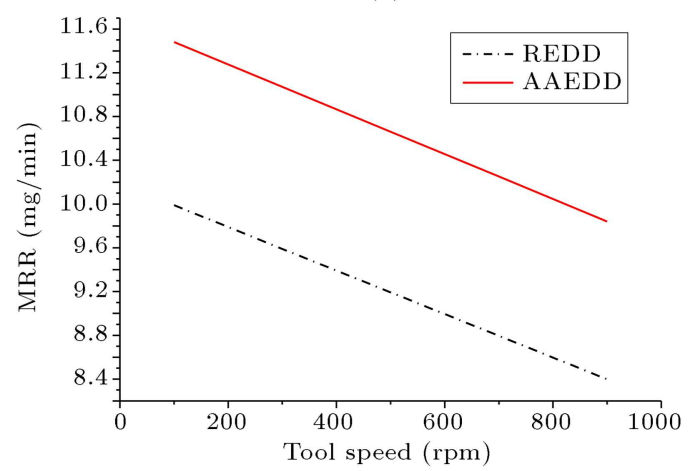

(c) pressure, the plasma can be quickly moved and severed, and re-casted on the surface of the specimen resulting in high surface roughness [12].

\section{Results and discussion}

\subsection{Effect of process factors on $M R R$}

The impact of discharge current during AAEDD and REDD processes is shown in Figure 7(a). MRR enhanced with an increase in discharge current. This was presumably due to the enhancement of discharge energy in the zone of machining, which causes increased melting and evaporation of material [24]. From plot (Figure $7(\mathrm{a})$ ) it can be inferred that MRR during AAEDD was relatively higher concerning MRR of the REDD process. This is because the density of spark energy increased with an enhancement in discharge current which caused a large crater volume [25]. The electrical energy provided to generate a single spark in $\mathrm{EDM}$ is given by $Q=V_{g} I T_{\text {on }}$, where " $V_{g}$ " is the voltage of the gap, " $I$ " is the discharge current, and " $T_{\text {on }}$ " is the pulse on time. Das et al. [31] observed a decrease in the energy density due to the increase of the spark radius. As a consequence, the energy density of the " $U$ " spark is given by:

$$
U=\frac{Q}{\pi r^{2} l}=\frac{V_{g} I T_{o n}}{\pi r^{2} l}
$$

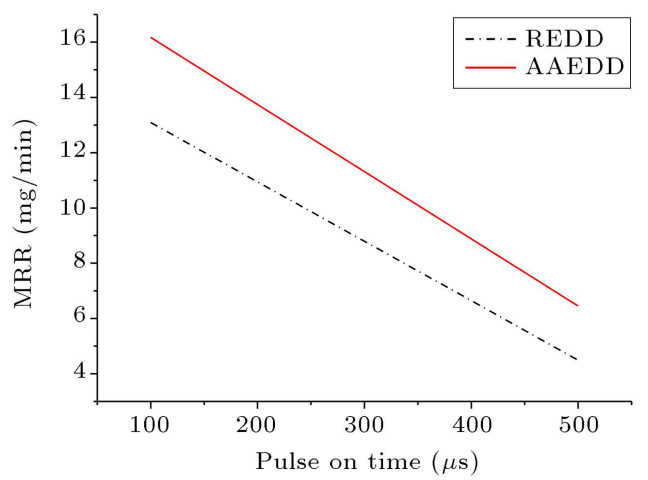

(b)

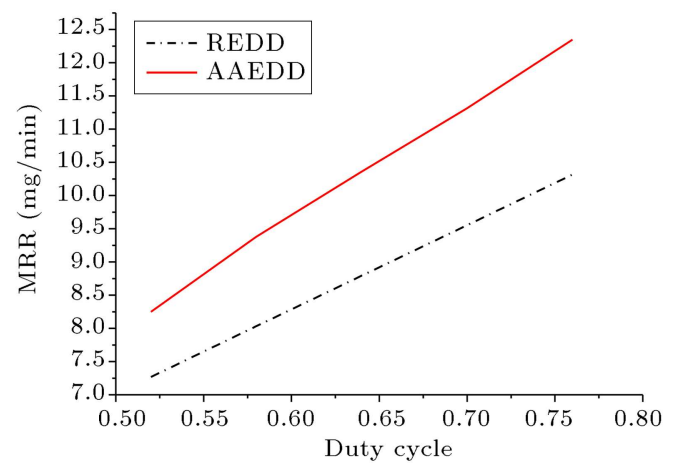

(d)

Figure 7. Influence of (a) discharge current, (b) pulse duration, (c) tool speed, and (d) duty cycle on Material Removal Rate (MRR). 
where " $r$ " is the plasma radius and "l" is the interelectrode gap. It can be concluded from the above mentioned relationship that the density of the spark energy increased with an increase in the discharge current [32]. The oxygen in the air induces an exothermic reaction that produces additional heat for material removal in AAEDD [27]. The molten metal of the steel workpiece reacts with oxygen from the air and releases heat. The reaction is exothermic, which transfers heat to the discharge crater as expressed by this chemical reaction $\left(2 \mathrm{Fe}+1.5 \mathrm{O}_{2} \rightarrow \mathrm{Fe}_{2} \mathrm{O}_{3}+\right.$ heat $)$ [33]. However, the multi-hole tool with slot facilitated the effective spreading of dielectric, as this speed up the removal of eroded maters from the spark zone. The influence of pulse-on time on MRR, during AAEDD and REDD processes, is shown in Figure 7(b). With an increase in the pulse period, MRR was decreased. During REDD, a long pulse-on time resulted in an expansion of the plasma channel, so the energy density is reduced. Because of less melting and vaporization of the workpiece, the decreased MRR was observed at prolonged pulse duration [34]. Therefore, in contrast to the REDD, it could be seen that AAEDD had more MRR. This was probably because the supply of compressed air through a multi-hole slotted rotary tool resulted in a better removal of evaporated and molten material from the discharge gap. The influence of tool speed on the MRR during REDD and AAEDD is shown in Figure 7(c). From the plot, it can be seen that for both processes, at high values of tool rotation the MRR decreased. This was probably due to the reason that excessive tool rotation resulted in enhanced turbulence, which disturbed the plasma channel. The high tool speed resulted in an exorbitant centrifugal force that caused a whirl of dielectric liquid through the electrode gap [11]. Figure 7(d) shows the impact of the duty cycle on MRR during REDD and AAEDD. With an improvement in the duty cycle, the MRR has improved. It was possibly because the intense spark energy released during a high duty cycle triggers the enhanced melting of the specimen [24]. It could be seen from the diagram that MRR during AAEDD was better than the REDD process. It was most likely due to the use of a multi-hole slotted tool which helped to extract eroded particles and heat from the machining area quickly. Thus, it improved the flushing action during operation which in turn resulted in high MRR.

\subsection{Effect of process factors on $E W R$}

In the EDM process, the cavity to be generated is governed by the tool electrode. An ideal EDM tool electrode should be electrically conductive with a low wear rate and should result in a better surface finish along the workpiece. The electrical erosion resistance is determined by the thermophysical and mechanical attributes of the EDM electrode [31].
The impact of discharge current on EWR during REDD and AAEDD is shown in Figure 8(a). For both processes, EWR was considered to be improved with a rise in the discharge current. This was presumably because high current produced additional discharge energy. This led to high temperatures in the machining area, which increased the wear of the electrode alongside MRR, thereby increasing the wear ratio of the electrode [10]. Moreover, at high discharge current, a lot of disintegrated particles get amassed in the machining gap that in the end enhanced the electrode wear [21]. From Figure 8(a), one can see that in AAEDD, EWR was lower than in the REDD. This behavior was due to the reason that as the highpressure air is passed through the multi-hole slotted electrode, it produced a cooling effect on the surface of the electrode, and due to this the crater produced during the AAEDD process reduced on the tool surface [12]. Figure 8(b) presents the effect of pulse on time on EWR. As illustrated in this figure, it can be seen that EWR had an inverse correlation with a pulse on time. This is possibly due to the fact that the expansion of the plasma channel occurred at a high value of pulse on time, which reduces the energy density and results in low electrode wear [21]. Besides, the black carbon is produced by cracking the hydrocarbon oil that gets deposited on the electrode surface at a longer pulse duration. The deposited layers of carbon protected the tool against excess wear of the tool electrode [7]. Further, from the plot, it could be observed that EWR was lowered in AAEDD in comparison to the REDD process. It was probably due to the reason that the temperature of the tool decreased by compressed air which limited the additional melting of the tool and subsequently decreasing its wear. Figure 8(c) represents the effect of the duty cycle on EWR for AAEDD and conventional REDD process. It shows that EWR enhanced in direct correlation with the duty cycle. High spark energy was liberated because of increase in a duty cycle which in due course initiated a high EWR [30]. It could be concluded from the plot that EWR in the AAEDD was less in comparison to the REDD process. This was because the multi-hole slotted rotary tool used during the AAEDD process enhanced flushing efficiency in the zone of machining by effectively removing the eroded particles and heat. The impact of tool rotation on EWR for the AAEDD and conventional REDD is shown in Figure 8(d). From the graph, it can be observed that EWR increased with increased tool speed for both processes. The extent of centrifugal force expanded with an enhancement in electrode rotational speed. The black carbon was released by cracking of dielectric stick on the surface of the electrode. This tends to increase the ability of the tool against wear. Yet, by increasing the centrifugal force the layer of carbon slipped out from 


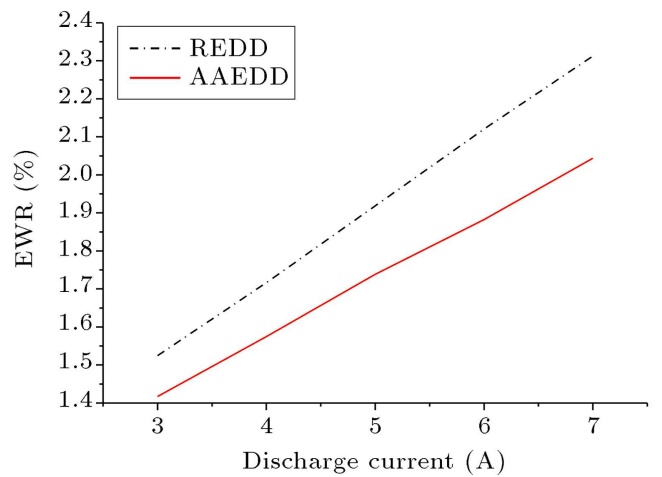

(a)

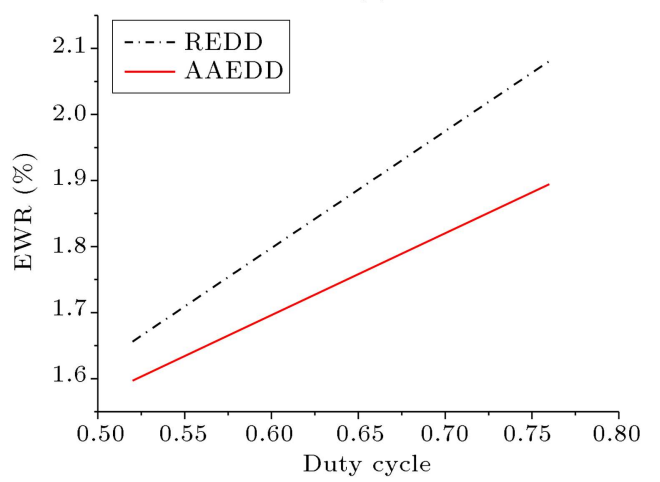

(d)

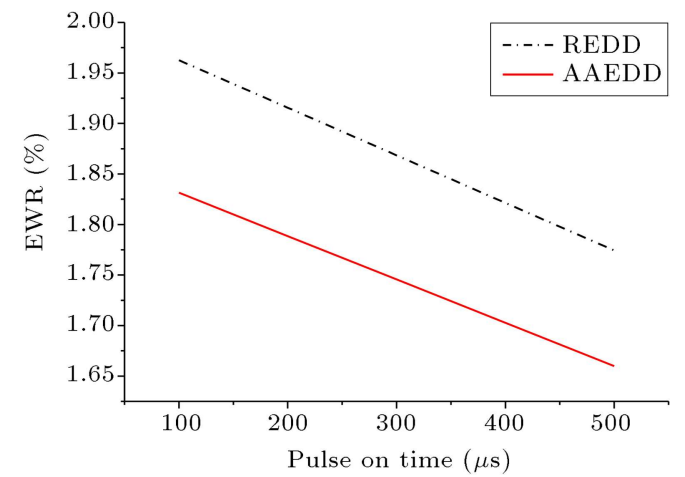

(b)

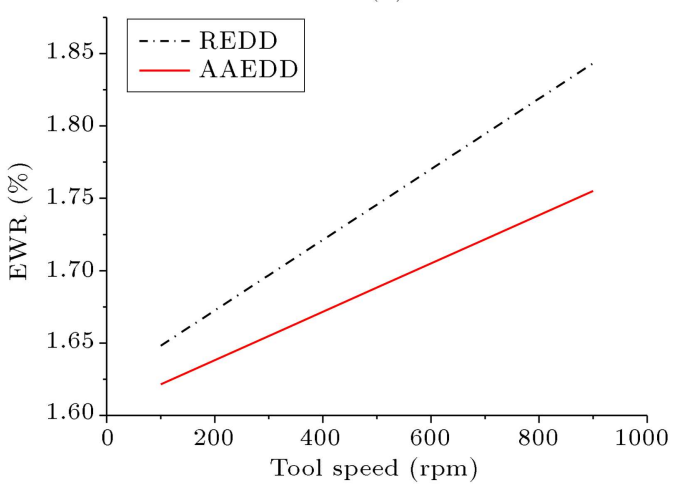

(c)

Figure 8. Effect of (a) discharge current, (b) pulse duration, (c) duty cycle, and (d) tool speed on Electrode Wear Ratio (EWR).

the surface of the tool which brought about increased tool wear [28]. Furthermore, the flushing efficiency of the discharge gap is likely to improve, when the rotation of the electrode is increased. Because of this the number of eroded particles in the machining gap was reduced and caused a high value of EWR [31]. Moreover, it can be seen clearly from the plot that EWR was more in traditional REDD when contrasted with the AAEDD process. It was probably because the compressed gas resulted in a faster solidification of suspended carbon (on tool surface) due to the breakdown of dielectric. Moreover, the cooling of the electrode surface felicitated the formation of carbon layers. The cooling effect is produced because the flow of air through the electrode removes heat and reduces the temperature of the tip of the electrode $[13,14]$. Hence, when compressed air was passed through the tool the formation of carbon deposition increased.

\subsection{Influence of process parameters on $S R$}

The effect of discharge current on SR during REDD and AAEDD is presented in Figure 9(a). It can be seen clearly from the plot that the SR of both processes enhanced with an increase in discharge current. The discharge energy increased with increment in discharge current. The available large discharge energy and impetuous force created an intense and large-sized carter on a workpiece, as a consequence, the surface finish deteriorated with an increase in discharge current [29]. From Figure 9(a) it can also be seen that SR was higher in AAEDD in contrast to REDD. This may be the reason that the compressed air and rotation of electrode allowed more molten material to be dislodged by each discharge resulting in a deep crater, causing high $\mathrm{SR}$ in the AAEDD process in comparison to the REDD process.

Figure 9(b) depicts the correlation between SR and pulse on time. An improvement in SR was found with an increase in pulse on time while machining with tool rotation. The enlargement of the plasma channel occurred in the discharge gap with a rise in pulse on time, because of which, the density of discharge current reduced. Thus, the development of a shallow crater occurred on a specimen, which ultimately decreased the SR [30]. It was inferred from the plot that the SR was higher during the AAEDD process in comparison to the REDD process. It was most likely due to the reason that with a decrease in impulsive force, the debris could not be extracted thoroughly from the electrode gap and the cooling effect caused by compressed air in case of the AAEDD process caused the emergence of recast layer, which ultimately degraded the surface quality [12]. For AAEDD and traditional REDD process, Figure 9(c) shows the effect of the duty cycle on SR. It shows that the SR increased in direct correlation with 


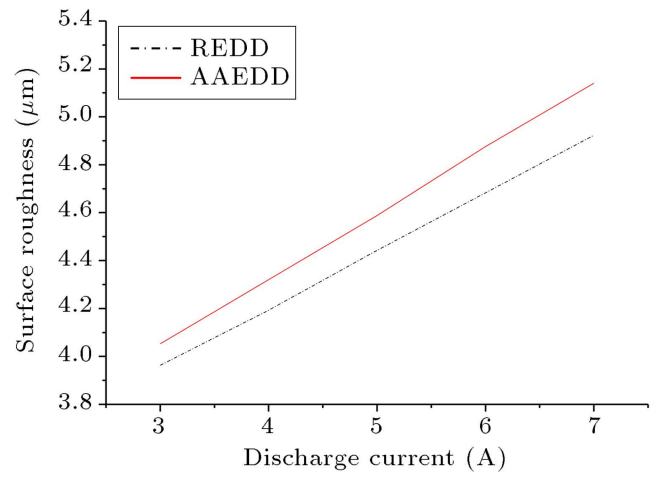

(a)

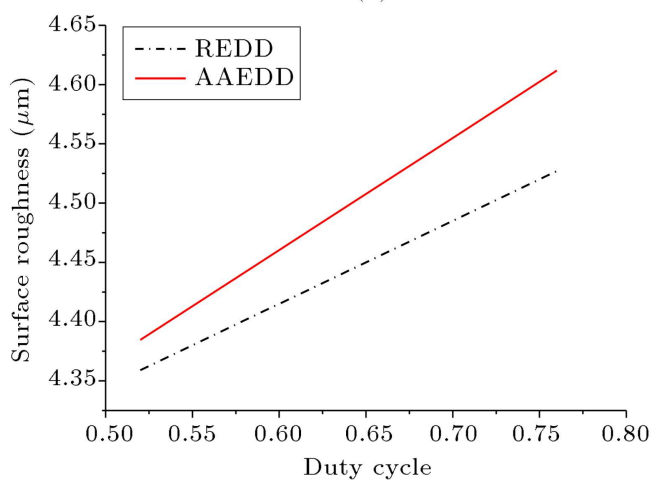

(d)

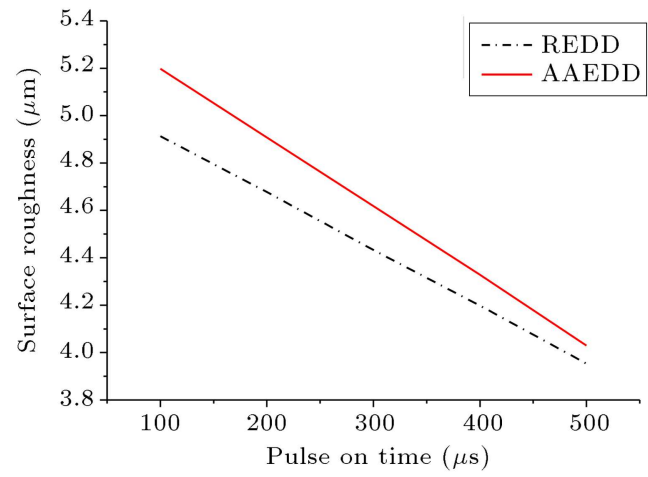

(b)

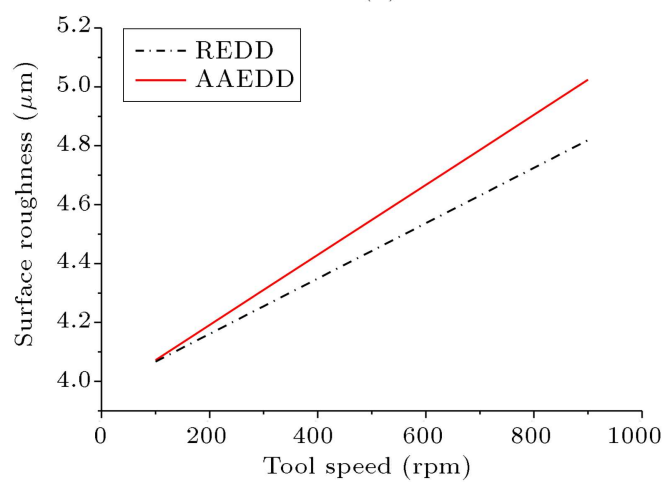

(c)

Figure 9. Influence of (a) discharge current, (b) pulse duration, (c) duty cycle, AND (d) tool speed on Surface Roughness (SR).

the duty cycle. At low duty cycle, the energy density of the spark is lower which results in a very low degree of material removal. This provided adequate time for the removal of debris from the machining zone. Hence, fewer recast layers were formed at a low duty cycle, and as a result SR decreased [33]. Further, from Figure 9(c) it can be seen that SR was found more in AAEDD in comparison to REDD. This can be explained by the fact that the presence of oxygen content of air in AAEDD promotes an exothermic reaction which results in a larger spark and a large crater and leads to poor surface quality [13]. The impact of tool rotational speed on SR for AAEDD and the conventional REDD is presented in Figure 9(d). It can be inferred from the plot that, for both processes, SR increased with increment in electrode rotation. Because of the rotation of the electrode, the air moved radially outwards from the core and removed eroded particles from the discharge gap under the influence of centrifugal force. Because of the inefficient removal of eroded work material from the machining gap and under the influence of tool rotation the eroded particles get deposited. This caused a higher SR [20]. Further, SR was found more in the AAEDD as compared to the conventional REDD process (Figure 9(d)). This was possibly due to the fact that the recast layer increased due to the high-pressure air cooling and results in increased Surface Roughness (SR). As evident from Figure 9 the $\mathrm{SR}$ was found more in AAEDD in comparison to REDD. This was possibly due to the reason that in AAEDD, the supplementary heat due to the exothermic reaction resulted in a large discharge crater [14]. This eventually enhanced the roughness of the specimen even at the same discharge energy. To obtain the improved surface finish, instead of air, an inert gas can be used because it can prevent an exothermic reaction from taking place. Therefore, it is suggested that the first air-aided multi-hole slotted tool should be used during the rough cutting operation, and thereafter inert gas should be used for deep hole drilling thus providing the optimum surface finish.

\section{Surface morphology}

The potential difference between the tool and the workpiece is applied in EDM. As the potential difference has been established, electrons from the tool begin to pass towards the workpiece [29]. In EDM operation, the workpiece surface attained a high temperature due to a rapid and regular strike of highly frisky electrons. Because of high-temperature the material easily melted and cavities were formed on the surface of electrodes. In EDM process, the crack development begins, when the level of thermal stresses surpasses the fracture strength of the specimen [4]. The Scanning Electron Microscope (SEM) images are shown in Figure 10 which illustrates the formation of crack on the surface 


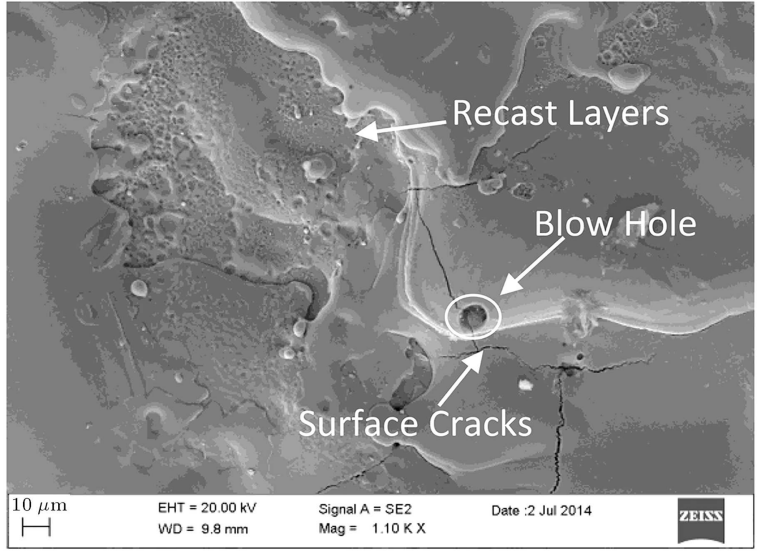

(a)

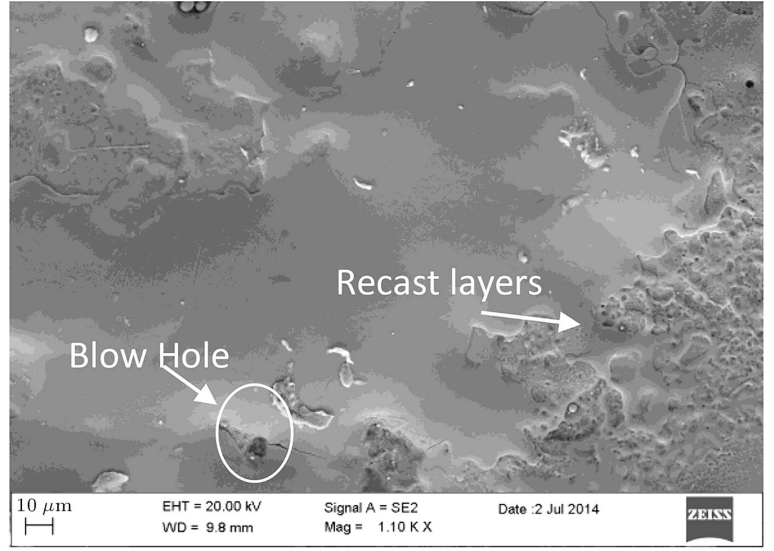

(b)

(i) Under, pulse on time of $300 \mu \mathrm{s}$, discharge current of $5 \mathrm{~A}$, tool rotation of $500 \mathrm{rpm}$, duty cycle of 0.64

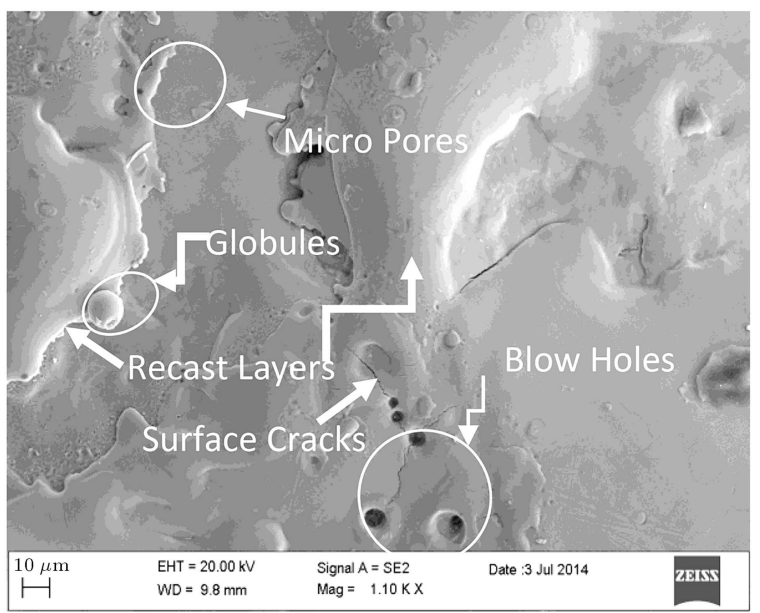

(a)

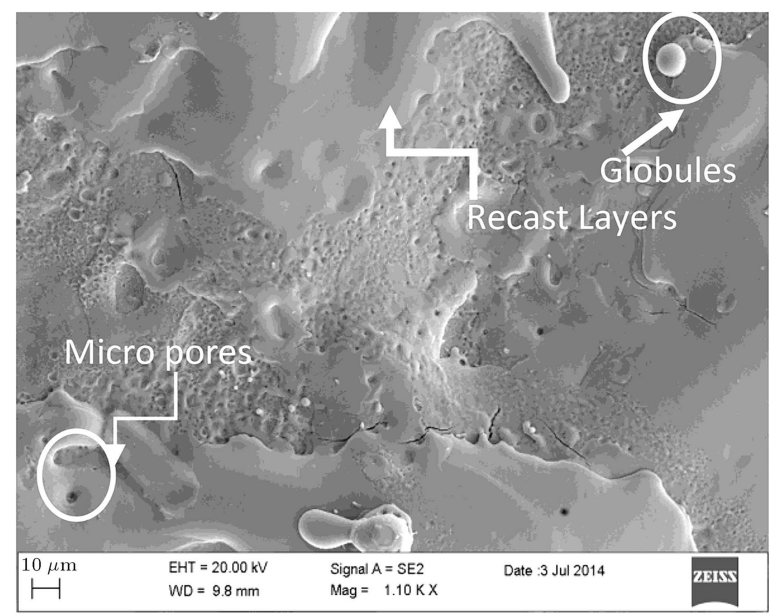

(b)

(ii) Under, pulse on time of $300 \mu \mathrm{s}$, discharge current of $7 \mathrm{~A}$, tool rotation of $500 \mathrm{rpm}$, duty cycle of 0.76 .

Figure 10. The surface characteristics of workpiece machined by (a) Rotary Electric Discharge Drilling (REDD) process and (b) Air Aided Electric Discharge Drilling (AAEDD) process.

of the machined specimens. From Figure 10 it can be observed that the workpiece machined through the REDD has more micropores, blow holes and surface cracks in comparison to the workpiece machined by the AAEDD process. This reduction in surface cracks may be attributed to electrode cooling (produced by compressed air), plasma channel temperature, and dielectric decreases near the tip of the tool. The effect is a decrease in the average temperature around the crater. This tends to result in a comparatively more uniform proportion of residual stress underneath the machined surface and induces a reduction in surface cracking. Similar conclusions have been presented by Srivastava and Pandey [35] for cryogenic assisted EDM. It was observed from SEM images that the workpiece machined by AAEDD had a smaller number of recast layers when compared to the REDD process. This was because when the compressed air flow was carried through the air-aided multi-hole slotted tool, it produced more turbulence and cavitation, resulting in a quicker expulsion of the molten metal. This improved the removal rate and did not allow the machined debris to settle and re-solidify as a white layer $[32,36]$.

\section{Process optimization and accuracy of models}

The various calculated responses and parameters are often uncertain because of experimental error. The accuracy of the process responses was calculated by estimating the CI using the relation, determined using the relation $Y \pm \Delta Y$, where, $\Delta Y$ is represented by:

$$
\Delta Y=t_{\alpha_{/ 2}}, \quad D F \sqrt{V_{e}} .
$$

Here the process responses, EWR, MRR, and SR are denoted by $Y$. The level of the CI is indicated by $\alpha$ and 
Table 7. Optimum process parameters.

\begin{tabular}{cccccccc}
\hline Response & \multirow{2}{*}{$\boldsymbol{I}_{\boldsymbol{p}}(\mathbf{A})$} & $\boldsymbol{T}_{\boldsymbol{o n}}(\boldsymbol{\mu s})$ & DC & $\mathbf{r p m}$ & $\begin{array}{c}\text { AP } \\
\text { (mm of Hg) }\end{array}$ & $\begin{array}{c}\text { Optimum value } \\
\text { from model }\end{array}$ & $\begin{array}{c}\text { Experimental } \\
\text { result }\end{array}$ \\
\hline Maximum MRR (mg/min) & 7 & 100 & 0.76 & 500 & 15 & $27.9658 \pm 2.377$ & 28.3125 \\
Minimum EWR $(\%)$ & 3 & 100 & 0.52 & 100 & 3 & $0.8640 \pm 0.3124$ & 0.8431 \\
Minimum SR $(\mu \mathrm{m})$ & 3 & 500 & 0.52 & 900 & 3 & $0.6163 \pm 0.4771$ & 0.8861 \\
\hline
\end{tabular}

Note: MRR: Material Removal Rate; EWR: Electrode Wear Ratio; SR: Surface Roughness.

its value is selected as 0.05 . The variance of error of the foreseen procedure output is indicated by $V_{e}$. The effectiveness of EDM experiments can be increased to a large scale by the optimization of machining factors. The machining factors include both electrical and nonelectrical parameters. The electrical parameters such as discharge current, pulse duration, and duty cycle, and non-electrical parameters including tool speed and the discharge gas pressure have a major influence on EDM performance $[1,2]$. The fmincon a toolbox of MATLAB 12.0 was used to get optimum levels of process factors for minimum EWR, maximum MRR, and better surface finish, which are listed in Table 7 .

\section{Conclusions}

In the present study, an air-aided multi-hole slotted electrode was successfully used for the machining of the D3 die steel workpiece. This study investigated the effectiveness of the air-aided multi-hole slotted tool to increase the flushing efficiency of the discharge gap to improve the material removal mechanism during Electrical Discharge Machining (EDM) drilling. follows:

The findings of this study are summarized as

- A comparative analysis of output responses in the case of a solid rotary electrode and the air-aided multi-hole slotted rotary electrode was presented. High Material Removal Rate (MRR) and low Electrode Wear Ratio (EWR) were achieved through AAEDD in comparison to the Rotary Electric Discharge Drilling (REDD). Moreover, the Surface Roughness (SR) of the AAEDD process was relatively higher than that of the REDD process;

- It was probably the use of the multi-hole slotted tool that helped the rapid removal of eroded materials and heat from the machining area that the MRR was increased by 40-80\%. The EWR was reduced by $17-25 \%$, presumably because the tool temperature decreased by compressed air, which subsequently limited the additional melting of the tool and reduced its wear;

- Moreover, in the AAEDD process, the extra heat other than the heat generated by the spark resulted in the larger discharge crater on the machined surface, which gradually increased the roughness of the workpiece by approximately $9-15 \%$ compared to the REDD process;

- Statistical models have also been developed to predict responses such as EWR, MRR, and SR during the AAEDD process. Experimental inference suggested that the MRR was especially affected by the discharge current, pulse duration, and duty cycle, while the EWR was significantly affected by the discharge current, pulse duration, and tool rotation. The SR was notably influenced by discharge current, pulse duration, and discharge air pressure;

- The surface analysis showed that the recast layers on the AAEDD machined samples were less pronounced compared to the REDD process. In addition, it was also revealed that the surface cracks caused during the AAEDD process were less compared to the REDD process resulting in improved surface integrity;

- The optimal value of Electrical Discharge Drilling (EDD) parameters was observed to yield MRR, EWR, and SR comparable to $28.3125 \mathrm{mg} / \mathrm{min}$, $0.8431 \%$ and $0.8861 \mu \mathrm{m}$, respectively;

- Since air is cheaper and more available than commercially available inert gases, it is suggested that the air-aided multi-hole slotted tool should be used during rough cutting operation, then the inert gas should be used for deep hole drilling when optimum surface finish is needed.

\section{Future work}

The findings discussed in this paper can be further applied in the following ways:

1. The effectiveness of the air-aided multi-hole rotary slotted tool was proved to be successful. Further investigation should include the integration of ultrasonic actuation of the workpiece with the gasassisted multi-hole rotary slotted tool to improve the flushing efficiency of the process;

2. Mathematical modeling of the air-assisted rotary EDD process may be performed in the near future; 
3. The heat-affected zone of the machined work sample by REDD and AAEDD may be examined if there is a difference in Heat-Affected Zone (HAZ) of the REDD and AAEDD processes;

4. Some studies which considered the measurement of micro/nano hardness may be a better option for quantifying the thickness of the recast layer and the heat affected region.

\section{References}

1. Ho, K.H. and Newman, S.T. "State of the art electrical discharge machining (EDM)", Int. J. of Mach. Tools and Manuf., 43, pp. 1287-300 (2003).

2. Singh, N.K., Pandey, P.M., Singh, K.K., et al. "Steps towards green manufacturing through EDM process: A review", Cogent Engineering, 3, p. 1272662 (2016).

3. Singh, N.K., Pandey, P.M., and Singh, K.K. "Experimental investigation into the performance of EDM using argon gas-assisted perforated electrodes", Mater. Manuf. Proc., 32(9), pp. 940-951 (2017).

4. Wang, C.C. and Yan, B.H. "Feasibility study of rotary electrical discharge machining with ball burnishing for $\mathrm{Al}_{2} \mathrm{O}_{3} / 6061 \mathrm{Al}$ composite", Int. J. of Mach. Tools and Manuf., 40, pp. 1403-1421 (2000).

5. Singh, A., Kumar, P., and Singh, I. "Electrical discharge drilling of metal matrix composites with different tool geometries", J. of Proc. Mech. Engg., 227(8), pp. 1245-1249 (2013). DOI: $10.1177 / 0954405413484726$

6. Aliakabari, E. and Baseri, H. "Optimization of machining parameters in rotary EDM process by using the Taguchi method", Int. J. Adv. Manuf. Technol., 62(9-12), pp. 1041-1053 (2012).

7. Teimouri, R. and Baseri, H. "Effects of magnetic field and rotary tool on EDM performance", $J$. of Manuf. Proc., 14(3), pp. 316-322 (2012). DOI: 10.1016/j.jmapro.2012.04.002

8. Gholipoor, A., Baseri, H., and Shakeri, M. "Investigation of the effects of magnetic field on neardry electrical discharge machining performance", Proc IMechE Part B: J. Eng. Manuf., 230(4), pp. 744-751 (2015).

9. Gu, L. and Zhao, W. "Electrical discharge machining of Ti6Al4V with a bundled electrode", Int. J. of Mach. Tools and Manuf., 53, pp. 100-106 (2012).

10. Zhao, W., Li, L., and Gu, L. "Influence of flushing on performance of EDM with bunched electrode", Int. J. of Mach. Tools and Manuf., 58, pp. 187-194 (2012).

11. Xu, H., Gu, L., and Zhao, W. "Influence of flushing holes on the machining performance of blasting erosion arc machining", Proc. IMechE Part B: J. Eng. Manuf, 231(11), pp. 1949-1960 (2012). DOI: $10.1177 / 0954405415616585$

12. Singh, N.K., Pandey, P.M., and Singh, K.K. "EDM with air assisted multi-hole tool", Mater. Manuf. Proc., 31(14), pp. 1872-1878 (2015).
13. Kuineda, M. and Furuoya, S. "Improvement of EDM efficiency by supplying oxygen gas into gap", CIRP Annals: Manuf. Technol., 40, pp. 215-218 (1991).

14. Beravala, H. and Pandey, P.M. "Experimental investigations to evaluate the effect of magnetic field on the performance of air and argon gas assisted EDM processes", J Manuf Process., 34, pp. 356-373 (2018).

15. Wang, X. and Shen, Y. "High-speed EDM milling with in-gas and outside-liquid electrode flushing technique", Int J Adv Manuf Technol., 104, pp. 3191-3198 (2019).

16. Sher, F., Sajid, Z., Tokay, B., et al. "Study of gasliquid mixing in stirred vessel using electrical resistance tomography", Asia-pacific J. Che. Engg., 11(6), pp. 855-865 (2019).

17. Li, G. and Wataru, N. "Realization of micro EDM drilling with high machining speed and accuracy by using mist deionized water jet", Prec. Engg., 61, pp. 136-146 (2020).

18. Nastasi, R. and Koshy, P. "Analysis and performance of slotted tools in electrical discharge drilling", CIRP Annals-Manuf. Technol., 63, pp. 205-18 (2014). DOI: 10.1016/j.cirp.2014.03.054

19. Yan, B.H., Huang, F.Y., Chow, H.M., et al. "Microhole machining of carbide by electric discharge machining", J. Mate. Proc. Tech., 87, pp. 139-145 (1999).

20. Kumar, R. and Singh, I. "Productivity improvement of micro EDM process by improvised tool", Precision Engineering, 51, pp. 529-535 (2018).

21. Kumar, S. and Dhanbalan, S. "Influence on machinability and form tolerance of Inconel 718 in EDM using different diameter multi-hole Cu electrodes", SN Appl. Sci., 1, p. 396 (2019).

22. Shara, N.K.A., Sher, F., George, A.Y., et al. "Electrochemical investigation of novel reference electrode $\mathrm{Ni} / \mathrm{Ni}(\mathrm{OH})_{2}$ in comparison with silver and platinum inert quasi-reference electrodes for electrolysis in eutectic molten hydroxide", Int. J. Hydrogen Energy, 44(50), pp. 27224-27236 (2019).

23. Shara, N.K.A., Sher, F., Iqbal, S.Z., et al. "Electro chemical study of different membrane materials for the fabrication of stable, reproducible and reusable reference electrode", J. Energy Chem., 49, pp. 33-41 (2020).

24. Patel, K.M., Pandey, P.M., and Rao, P.V. "Study on machinability of $\mathrm{Al}_{2} \mathrm{O}_{3}$ ceramic composite in EDM using response surface methodology", J. of Engg. Mater. Technol., 133(2), pp. 021004-1-021004-10 (2011).

25. Srivastava, V. and Pandey, P.M. "Performance evaluation of EDM process using cryogenically cooled electrode", Mater. Manuf. Proc., 27(6), pp. 683-688 (2012).

26. Mohan, B., Rajadurai, A., and Satyanarayana, K.G. "Effect of $\mathrm{SiC}$ and rotation of electrode on electric discharge machining of Al-Si composite", J. Mate. Proc. Tech., 124, pp. 297-304 (2002). 
27. Singh, N.K., Pandey, P.M., and Singh, K.K. "A semi-empirical model to predict material removal rate during air-assisted electrical discharge machining", J Braz. Soc. Mech. Sci. Eng., 41, p. 122 (2019). https://doi.org/10.1007/s40430-019-1623-0

28. Teimouri, R. and Baseri, H. "Study of tool wear and overcut in EDM process with rotary tool and magnetic field", Advances in Tribology, 2012, pp.1-8 (2012). DOI: $10.1155 / 2012 / 895918$

29. Koshy, P., Jain, V.K., and Lal, K. "Experimental investigation into electrical discharge machining with rotating disk electrode", J. of Precis. Engg., 15, pp. 6-15 (1993).

30. Chattopadhyaya, K.D., Verma, S., and Satsangi, P.C. "Development of empirical model for different process parameters during rotary electrical discharge machining of copper-steel (EN-8) system", J. Mate. Proc. Tech., 209(3), pp. 1454-1465 (2009).

31. Das, S., Klotz, M., and Klocke, F. "EDM simulation: finite element-based calculation of deformation, microstructure and residual stresses", J. Mater. Proce. Technol., 142, pp. 434-451 (2003).

32. Tao, J., Shih, A.J., and Ni, J. "Experimental study of the dry and near dry electrical discharge milling process", J. of Manuf. Sci. and Engg., 130(1), pp. 1-8 (2008).

33. Beravala, H. and Pandey, P.M. "Modelling of material removal rate in the magnetic field and air-assisted electrical discharge machining", Proc IMechE Part C: $J$ Mech. Engg. Sci., 234(7) pp. 1-12 (2019). DOI: $10.1177 / 0954406219892297$

34. Kuppan, P., Rajadurai, A., and Narayanan, S. "Influence of EDM process parameters in deep hole drilling of Inconel 718", Int. J. Adv. Manuf. Technol., 38, pp. $74-84$ (2008).

35. Srivastava, V. and Pandey, P.M. "Experimental investigation on electrical discharge machining process with ultrasonic-assisted cryogenically cooled electrode", Proc IMechE Part B: J. Eng. Manuf., 227(2) (2012).
36. Kuineda, M. and Yoshida M. "Electrical discharge machining in gas", CIRP Annals: Manuf. Technol., 46(1), pp. 143-146 (1997).

\section{Biographies}

Nishant K. Singh is an Associate Professor at HCST, Mathura (India). He earned his PhD from IIT, Dhanbad, masters in Production Engineering and B. Tech in Mechanical Engineering, Delhi College of Engineering. He has published more than forty research articles in reputed international journals. His research interests include tribology, micro-manufacturing and non-conventional machining processes.

Rajeev Kumar Upadhyay is Director of Hindustan College of Science \& Technology, Farah (Mathura) and has been Professor of Mechanical Engg at Anand Engg College Agra. He has also been a former faculty member of Department of Mechanical Engineering, DEI, Dayalbagh, Agra. He has authored three books of Mechanical Engineering.

Yashvir Singh is presently working as an Associate Professor in the Department of Mechanical Engineering, Graphic Era Deemed University, Dehradun. He has more than 12 years of teaching experience. His specialization includes areas like tribology, biofuels, lubrication, manufacturing, etc. He published various research papers in reputed journals and also reviewed various articles of the journals.

Abhishek Sharma has 17 years of international involvement in Academic Teaching and Research across recognized Indian and African Universities. He Publishes over fifty research articles in SCI/SCIE and SCOPUS indexed journals and other peer-reviewed journals, and serves as the Reviewer and Editorial Member in peer-reviewed journals and conferences. 